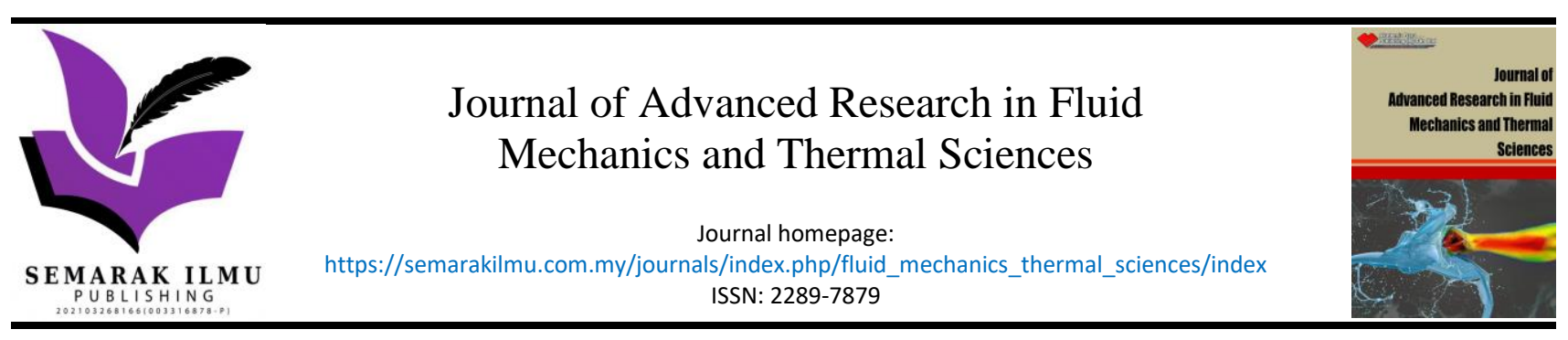

\title{
Coal Flowability Control on Preventing Spillage on Conveyor Belt Through Modeling and Simulation for Improving its Performance
}

\author{
Sabri Bahrun ${ }^{1, *}$, Mohd Shahrizan Yusoff $^{1, \star}$, Mohamad Sazali Said $^{1, \bullet}$, Azmi Hassan ${ }^{2, \star}$ \\ Manufacturing Section, Universiti Kuala Lumpur, Malaysian Spanish Institute Kulim Hi-Tech Park, 09000 Kulim, Kedah, Malaysia \\ 2 Electrical, Electronics and Automation Section, Universiti Kuala Lumpur, Malaysian Spain Institute Kulim Hi-Tech Park, 09000 Kulim, Kedah, \\ Malaysia
}

\section{ARTICLE INFO}

\section{Article history:}

Received 27 July 2021

Received in revised form 5 November 2021

Accepted 11 November 2021

Available online 15 December 2021

Keywords:

Settling zone; DEM simulation; controlling flowability; optimizing conveyor

\section{ABSTRACT}

Belt conveyors are generally used in mining plant areas, both surface and underground mines. The belt conveyor is mainly applied to transport the extracted bulk material from the mining site to delivery. The effectiveness of the extraction process depends on the reliability and durability of the conveyor belt system. In addition, conveyor performance is very important specially to control material flowability to prevent spills or other operational disturbances to optimize production throughput. However, the transfer chute and settling zone can cause some problems during the transfer process, such as material spills. This problem can reduce the function and performance of the conveyor belt. This paper discusses a design model to reduce the problem of spillage in the settling zone. The model was developed by compiling the previous defecting data from the durability of the conveyor system, then analyzed using Discrete Element Method (DEM) software and compared with bulk characteristics. The initial performance of certain conveyors is only capable of serving with an average production of $76 \%$ of the designed capacity while energy is consumed at full load. By applying the DEM simulation result, the blade gate can reduce the peak angle break in the depositional zone before exiting. After the analysis is completed using DEM, the conveyor increases the average production to $95 \%$ of the designed capacity. In conclusion, controlling the maximum belt load without spillage will reduce interruption on conveyor belt operation and maintenance costs therefore increase plant reliability and availability.

\footnotetext{
* Corresponding author.

E-mail address: sabri.bahrun@s.unikl.edu.my

* Corresponding author.

E-mail address: mshahrizan@unikl.edu.my

- Corresponding author.

E-mail address: msazali@unikl.edu.my

- Corresponding author.

E-mail address: azmi.hassan@unikl.edu.my
}

https://doi.org/10.37934/arfmts.90.1.130145 


\section{Introduction}

A belt conveyor is an important equipment to transfer bulk material that has been largely used in the mining industries. Availability and reliability of the conveyor system is a high level of the plant required to match the production target without any disruption. Controlling flowability with the appropriate load on the receiving belt is an essential issue to maximize the load capacity of the belt conveyor with effective power usage [1]

Even though a belt conveyor is carefully designed, material spillage from the carrying side of the belt may occur at the loading point and elsewhere along the belt conveyor[2]. Spillage is a condition when the bulk material falls from the side of the belt conveyor and the majority of the material can be everywhere aligned with the belt even underneath of the conveyor. Every spill of material will result in various impacts such as cleanliness in the surrounding area, double handling, unplanned downtime, and production losses.

Spillage occurs because of lack of control on flowability that impacted coal spill away from the belt. This condition can not apply coal conservation properly referring to company regulation. Interrupt the production when a system trip caused by the coal fall down hits the safety device. This also affected the safety aspect, blocking access on the walkway of conveyor, slippery surrounding area and forcing the wheel loader works in the crowded area of the structures. In addition, it can increase water usage to washdown the structure and increase the energy consumption to run the pump.

First, the three different angle positions of Figure 1 occur when the metal detector catches up the metal contamination and conveyor system trip, the coal is built up inside the settling zone with the formation and high peak of a repose angle. It restarts the conveyor system while the bulk material accelerates in uneven distribution. Second, unstable flow in the settling zone then the coal straightway outgoing from the receiving belt. Those are trigger spillages along the belt. The others risk of those material spilling away; breakdown production lines, damaging the components of the conveyor system, and environmental issues. Shutdown of the production line without planning impacted to reduce the throughput and delay the coal supply to customers.
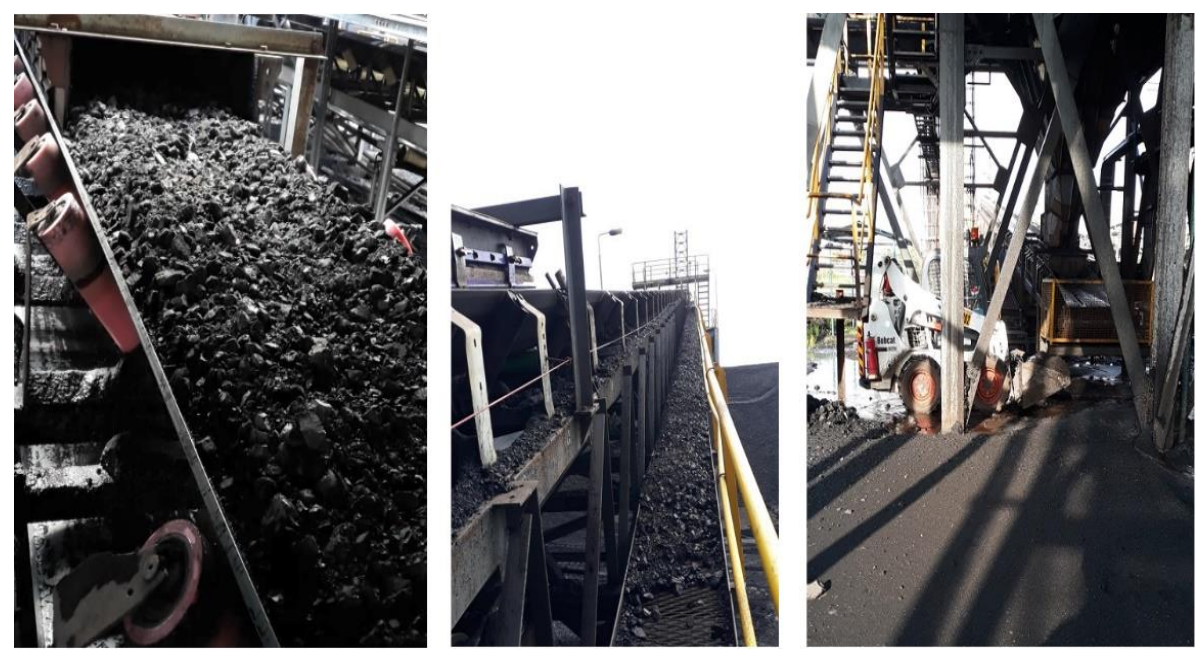

Fig. 1. Coal spill problem in real operation

Those phenomena of the material spill are unwanted occurrences and worst is it incur many major breakdowns in the conveyor system such as damaging the pulley lagging, ripping the belt, and overheating the electric motor. Hence, the operations are erratic. However, the conveyor system has program maintenance periodically: inspect the transfer chute, inspect mechanical include the belt 
and electrical component, lubrication system, replacing damaged components based on inspection finding and periodical service by meter reading and running condition-based maintenance (CBM). The approach for an analytic tool of this research is the DEM software in analysing material flow and table comparison for bulk material characteristics, calculation model also included to support modelling the tool. This research is promising on reducing the operational cost saving and increasing the plant availability and reliability. The extra benefit can be achieved such as having green operation of the belt conveyor and utilizing resources to the other works as the technician, operator, and equipment wheel loader. Furthermore, the management team can predict the production target more accurately. Each construction solution has its advantages and disadvantages and choosing the right one requires a detailed analysis of the conditions in which the conveyors cooperate. Analysis of the phenomenon occurring between the transported material and the elements of the transfer station is increasingly the subject of research conducted by many scientists [3].

The purpose of this paper is to introduce optimal control of the material flow to the belt conveyor system to improve the load capacity without any interruption and keep the cleanliness surrounding the area of the operations. This research is required for better understanding and build upon the existing knowledge of improvement of conveying systems impacted by spillages. However, adding a new component will generate new cost allocation for maintaining periodically to sustain the performance.

The layout of the paper is as follows: In Section 2, an overview of the transfer chute and settling zone, the angle for bulk material, conveyor load formula is reviewed. In section 3, works frame, data collection, measuring coal pattern on the belt conveyor, individual load, specification data, data analysis, and DEM modelling the tool are in the methodology. In section 4, the effect from the angle, coal characteristic against flowability, mechanical modelling and calculation for developing the tool, and performance indicator is in result and discussion. In section 5 , the last is the conclusion.

\section{Literature Review}

The settling zone part of the transfer point is located at the end of the transfer chute above the receiving conveyor as shown in Figure 2 . In an additional enclosed volume of the load zone after the product has been placed onto the belt. It is an enlarged portion of the covered skirt board area at the transfer point. The size of a settling zone should be determined by five factors: width and speed of the belt, width of chute, amount of airflow, depth of the material bed, and diameter of the largest lump material that may pass through the settling zone $[3,4]$. Improper design can result in dust liberation, leaking of fine coal, and coal spills to the ground.

There are several cross-section conditions that must be considered in the conveyor design. During loading with conventional chute, there is often a turbulent transition, a profile confined by the skirt boards and finally the unconfined condition on the belt where the bulk material cross-section at the angle of response settles to a steady-state profile governed by the surcharge angle. The capacity of a belt conveyor depends on the bulk material surcharge angle, the troughing angle of the idlers, and the bulk density [4]. 


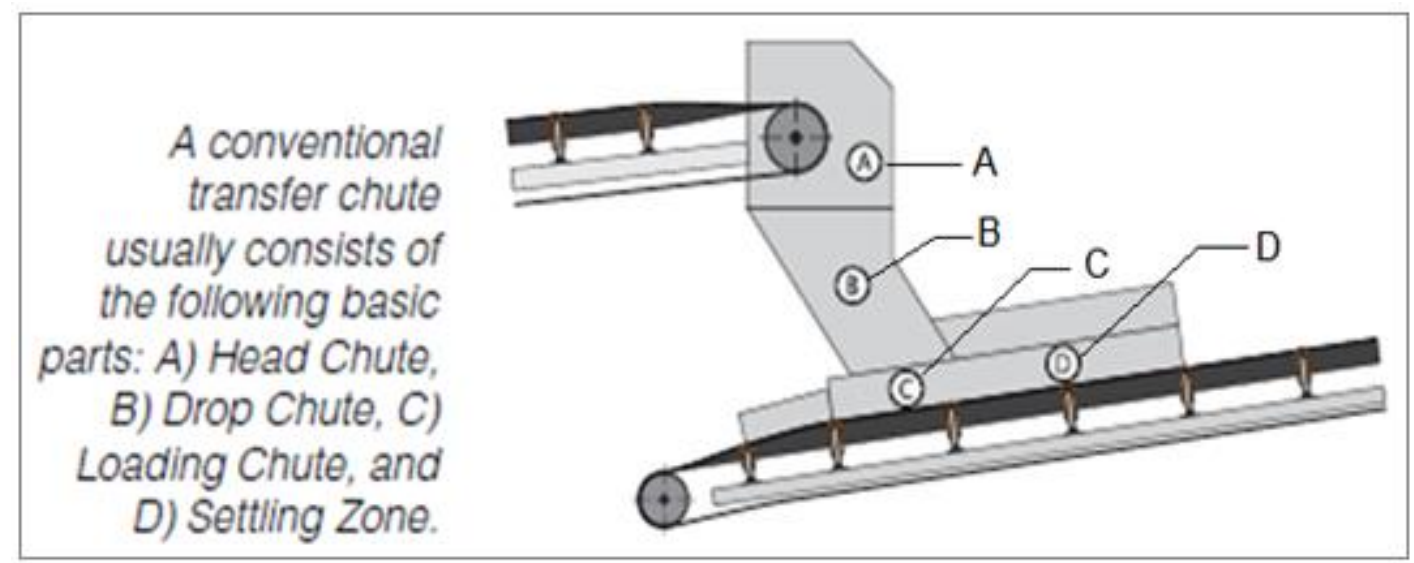

Fig. 2. Transfer chute overview

\subsection{Angle Repose and Angle Surcharge}

In the load of the bulk material, there are two terminologies of the angle as follows

a) Angle repose, when the bulk material is dropped on the horizontal surface (ground). It forms a conical heap with a certain inclination (angle) with the horizontal surface. The angle of repose $(\beta)$ of a material is the natural angle formed by gravity discharge of the material and measured from a horizontal base.

b) Angle surcharge, the material is dropped on the horizontal surface which is in vibrating condition or is having internal agitation. The material tends to settle/spread and will have a lesser inclination with the horizontal surface [5], as detail in Figure 3.

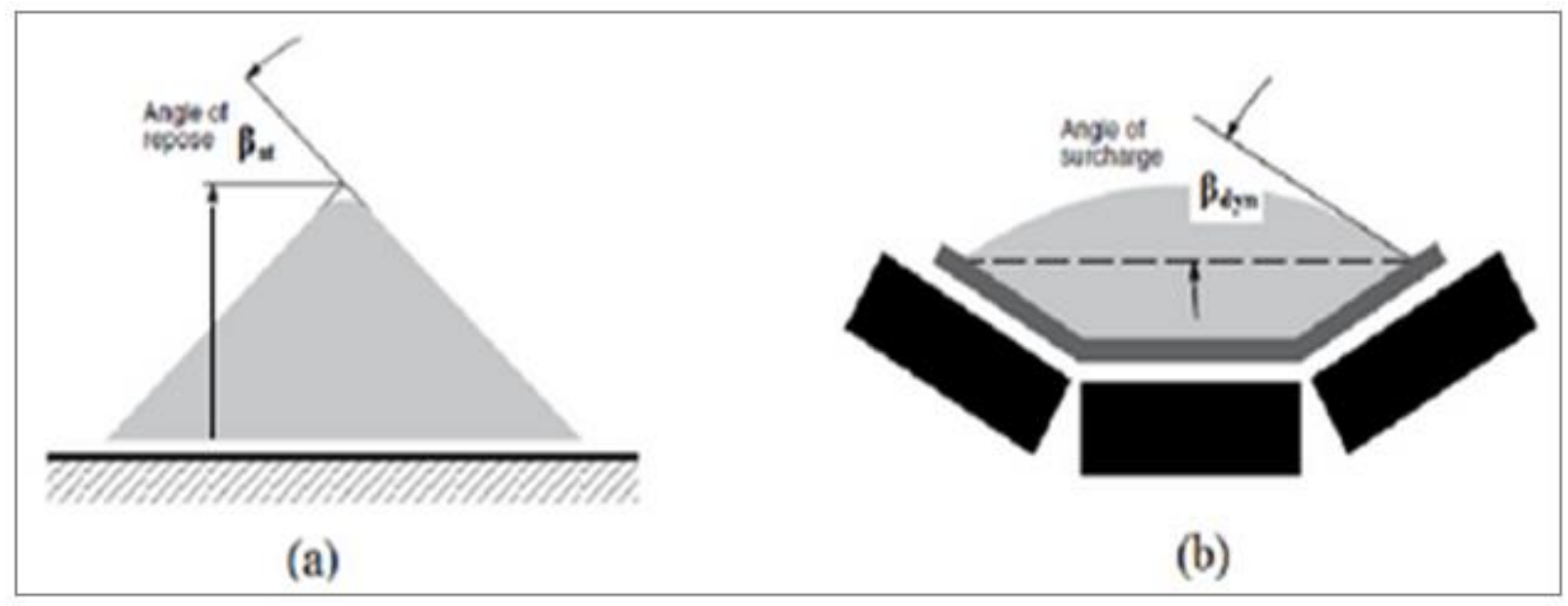

Fig. 3. Angle of bulk material load

The principal factors that influence the sizing of a belt conveyor are the required load volume, the type of transported material and its characteristics such as grain or lump size, and chemical or physical properties. The correct project design of the belt conveyor must begin with an evaluation of the characteristics of the conveyed material and in particular the angle of repose and the angle of surcharge. The angle of repose of a material, also known as the "angle of natural friction" is the angle at which the material, when heaped freely onto a horizontal surface, takes up to the horizontal plane $[6,7]$. 


\subsection{Troughed Belt Conveyor Capacity}

The capacity of a troughed belt is a function of the cross-sectional area of the load that can be carried, no spillage, the belt speed, and the bulk material density. To optimize the loading, the transversal area should be designed to ensure the most advantageous initial load. The Model is written as follows [7]

Load Capacity (metric) Qt $=3.6 \times$ At $\times \delta \times v(t / h)$

Qt $=$ Conveyor Capacity $\mathrm{t} / \mathrm{h}$

At $=$ Cross sectional area $\mathrm{m}^{2}$

$\delta=$ Bulk density of the material $\mathrm{kg} / \mathrm{m}^{3}$

$\mathrm{v}=$ Conveyor speed $\mathrm{m} / \mathrm{s}$

Figure 4 illustrates the basic components of a typical belt conveyor. In practice, according to the variety of uses, it is possible to have many other diverse combinations of load and unload areas, elevations, and other accessories to support the whole system. The correct project design of the belt conveyor must begin with an evaluation of the characteristics of the conveyed material and in particular the angle of repose and the angle of surcharge. The angle of repose of a material, also known as the "angle of natural friction" is the angle at which the material, when heaped freely onto a horizontal surface takes up to the horizontal plane $[7,8]$.

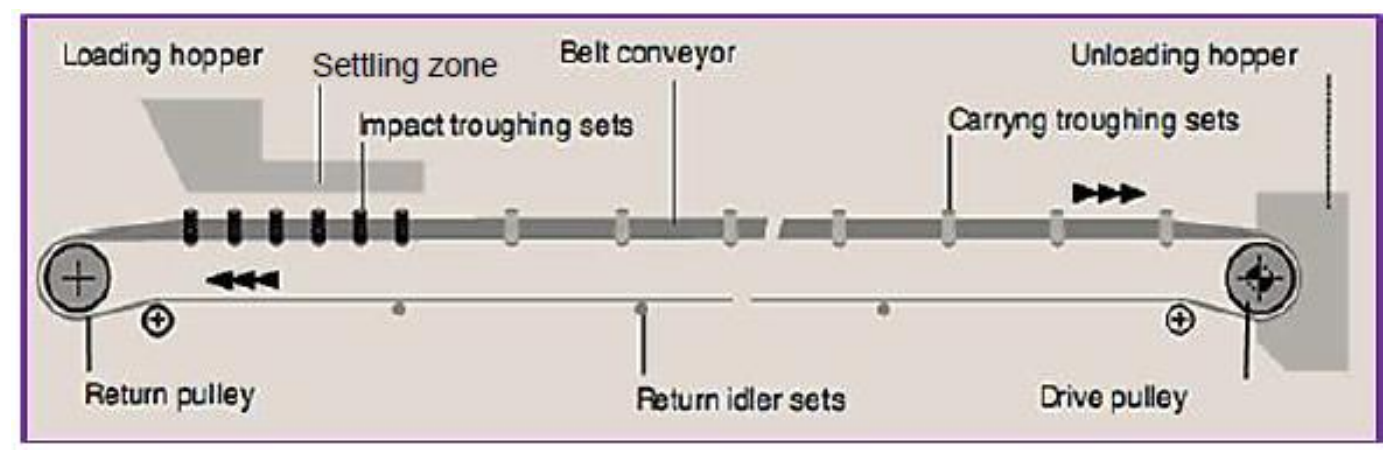

Fig. 4. Basic conveyor arrangement

\subsection{Troughed Belt Bulk Material Cross-Sectional}

The conveyed cross-section must be less than the allowable cross-section which varies with the belt width and several practices have shown to produce a safe design[4]. The bulk area of the crosssectional calculation model on the belt conveyor is as follows

$\mathrm{A}=\frac{\mathrm{Q} \cdot \mathrm{k}}{\mathrm{V} \cdot \gamma_{\mathrm{m}}}$

A = Bulk material cross sectional

$\mathrm{Q}=$ Material conveyed base on design requirement (Tph)

$\mathrm{k}=$ Conversion factor of inclination

$\mathrm{V}=$ Belt speed $(\mathrm{m} / \mathrm{s})$

$\gamma_{\mathrm{m}}=$ Bulk material density $\left(\mathrm{kg} / \mathrm{m}^{3}\right)$ 


\section{Methodology}

The model will consider the compilation of previous defecting data from the durability of the conveyor system. Modelling and simulation work then analysed using Discrete Element Method (DEM) software and compared against the bulk characteristic. A comparison is made between field observations and the material stream bed depth profiles obtained using the DEM. The cross-sectional bulk solid material stream profiles at loading are also assessed against those predicted by design guideline CEMA [8-10] the material velocity at loading is significantly lower than the receiving conveyor and incoming conveyor belt speed $[10,11]$.

The parameters to be considered such as particle size, angle, flow cantering, coal dynamic movement in the settling zone that all influences against the accelerate and flowability. Real particle size distribution of the coal ranges from fine powder in between $5-25 \mathrm{~mm}$, while lump size maximal $50 \mathrm{~mm}$. The result of the simulation will be used to deciding of the next step in the project. The research model details, can be seen in the chart as in Figure 5.

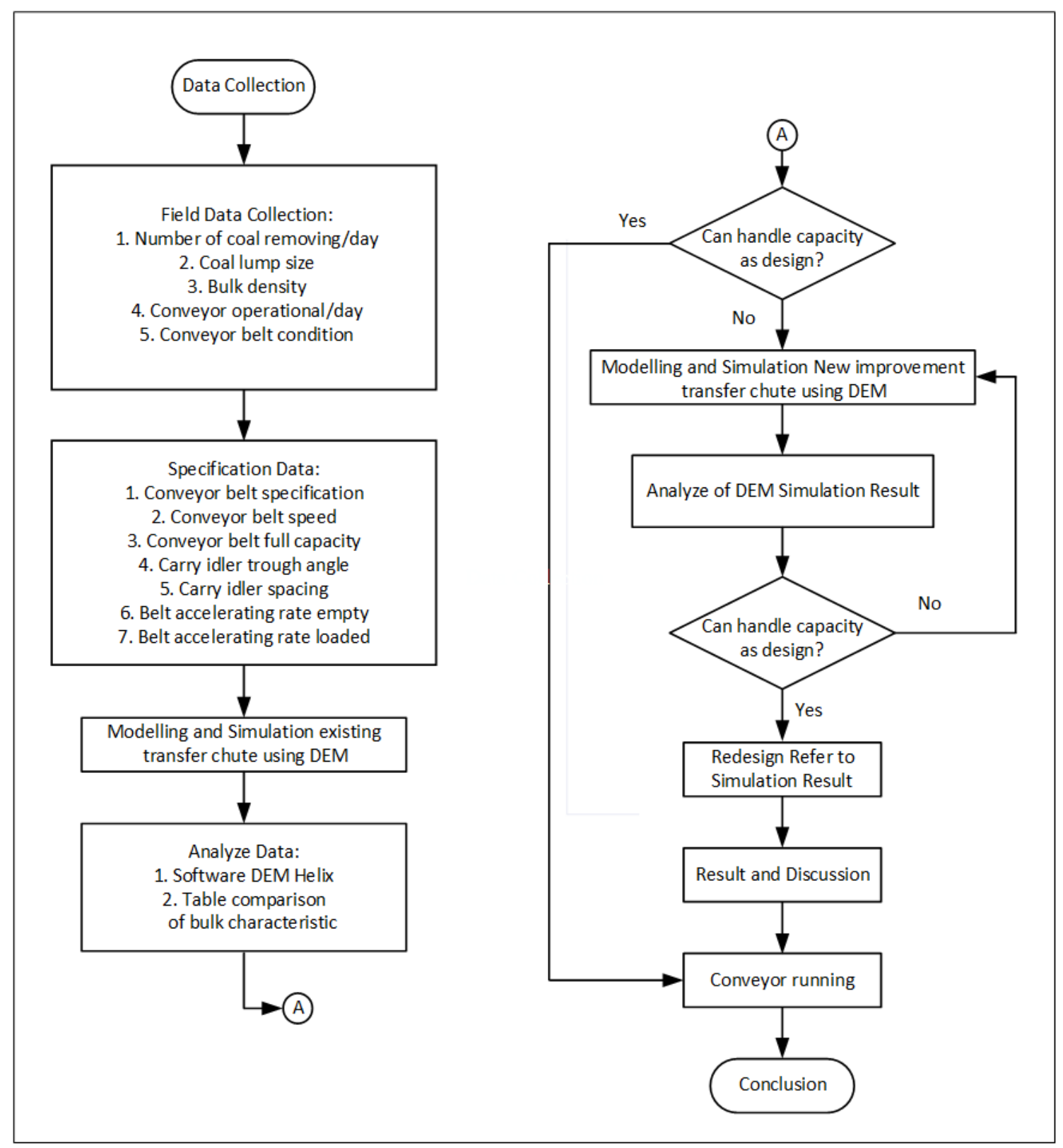

Fig. 5. Research model 


\subsection{Field Data Collection}

This section part of on-site condition as a sample before simulating [10], the data that is taken in a coal mining company in Central Kalimantan, the area of the processing plant where the conveyor operation is as the main equipment to transfer the product. A specific location is taken at the loading conveyor for measuring coal pattern as shown in Figure 6, load on the belt, coal lump size, documentation, and checking the environment surrounding the area. The result of the field data as in Table 1 while the individual load of the conveyors as in Figure 7. Table 2 shows conveyor basic specification.
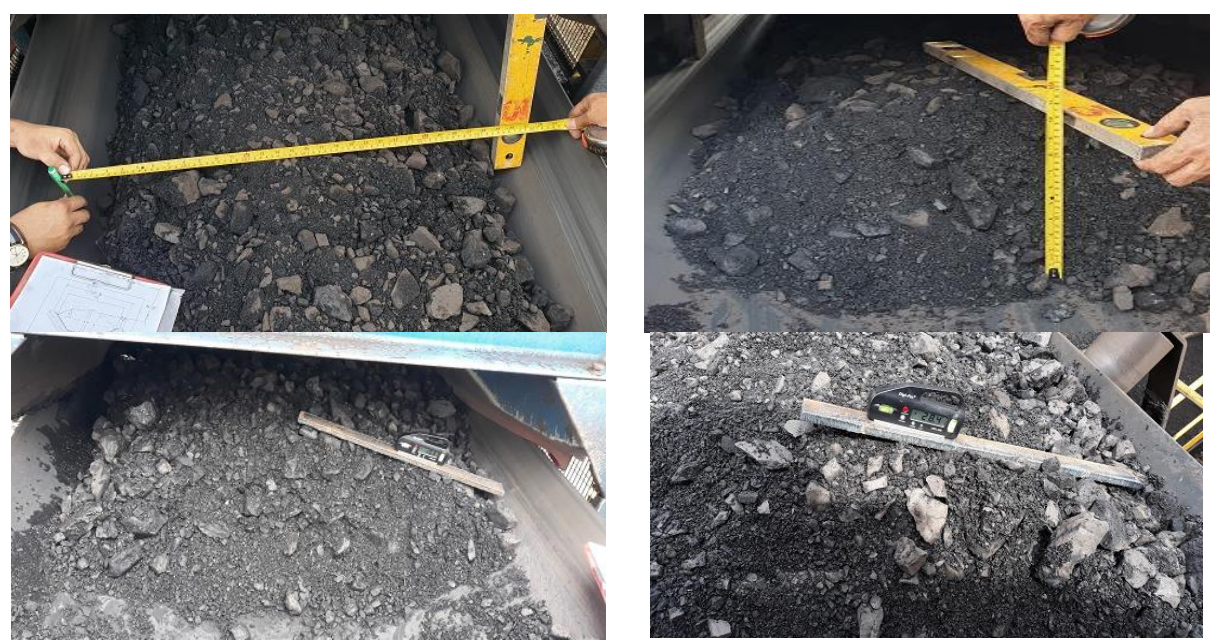

Fig. 6. Measuring coal pattern on the belt

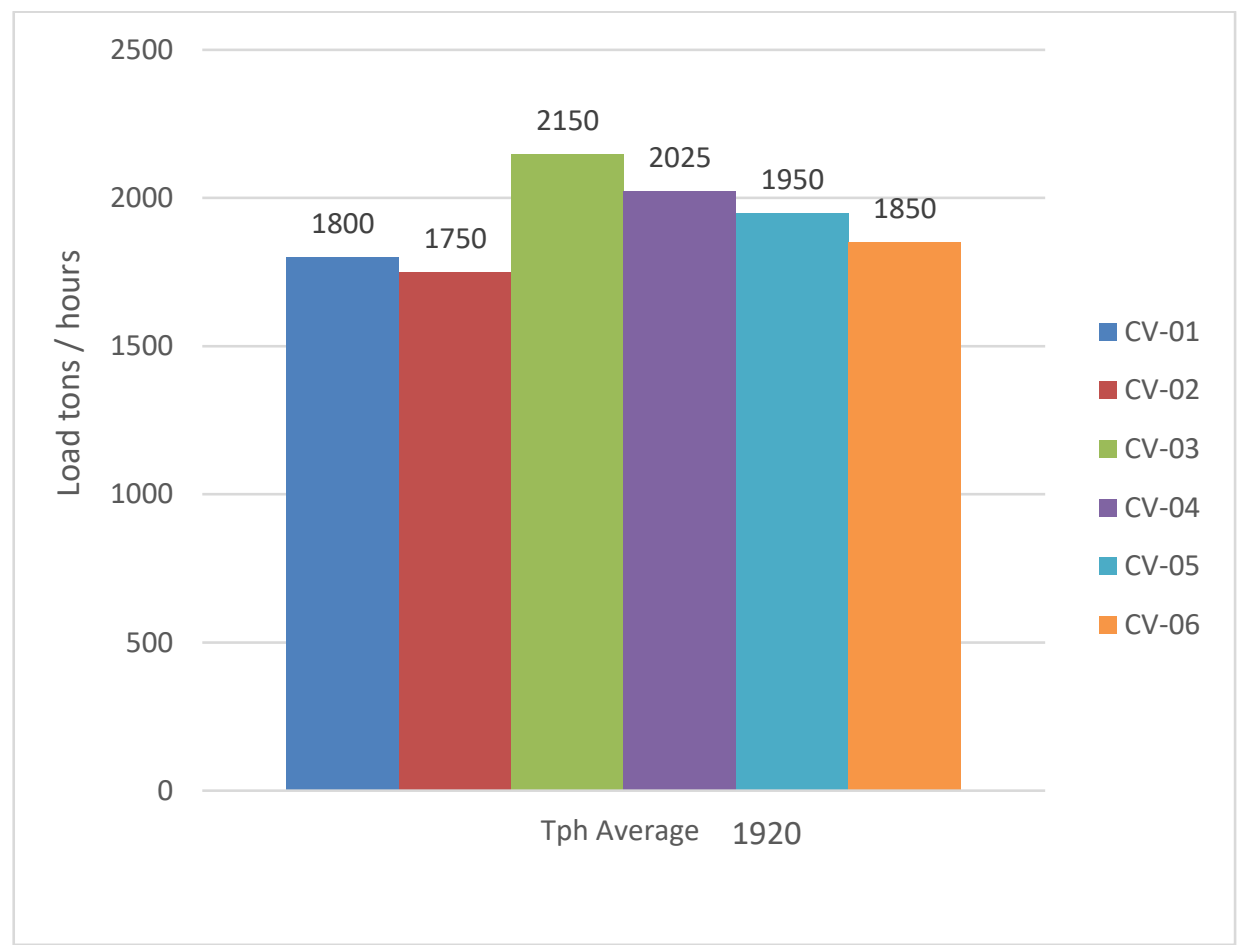

Fig. 7. Individual load of the conveyor 
Table 1

Field data of operational coal handling

\begin{tabular}{ll}
\hline Average No of coal removing/day & 42240 tons per day \\
Conveyor operating/day & 22 hours \\
Fine powder & $05-25 \mathrm{~mm}$ \\
Coal lump size & $30-50 \mathrm{~mm}$, the highest \\
Bulk density & $0.85 \mathrm{t} / \mathrm{m}^{3}$ \\
Belt condition & Good and proper to use \\
Environment & Material coal spill \\
\hline
\end{tabular}

Table 2

Conveyor basic specification

\begin{tabular}{ll} 
Belt specification & $\begin{array}{l}\text { Wide } 1200 \mathrm{~mm} \times 250 \mathrm{M} \text { Length, cover rubber } 6 \times 2 \mathrm{~mm}, 4 \mathrm{P}, 18 \mathrm{~mm} \\
\text { thickness, EP150 Grade M }\end{array}$ \\
Conveyor belt speed & $4.5 \mathrm{~m} / \mathrm{s}$ \\
Conveyor full capacity & $2500 \mathrm{Tph}$ \\
Carry Idler trough angle & $45^{0}$ \\
Carry Idler spacing & $1.2 \mathrm{M}$ \\
Starting time fully loaded & $8.17 \mathrm{~second}$ \\
Starting time empty & $1.53 \mathrm{~second}$ \\
Accelerating rate empty & $2.94 \mathrm{~m} / \mathrm{s}^{2}$ \\
Acceleration rate loaded & $0.55 \mathrm{~m} / \mathrm{s}^{2}$ \\
\hline
\end{tabular}

\subsection{Data Analysis}

To begin the analysis, primely review the material characteristics and basics of the conveyor specification that are inputted into Discrete Element Method (DEM) as a parameter. The software transmits the data as required such as angle of repose, surcharge and belt load area of utilization at the peak as seen in Figure 8. This section will be combined with a table comparison of characteristics as in Table 3, and preliminary simulation to establish the analysis process. Table 4 shows angle repose rate.

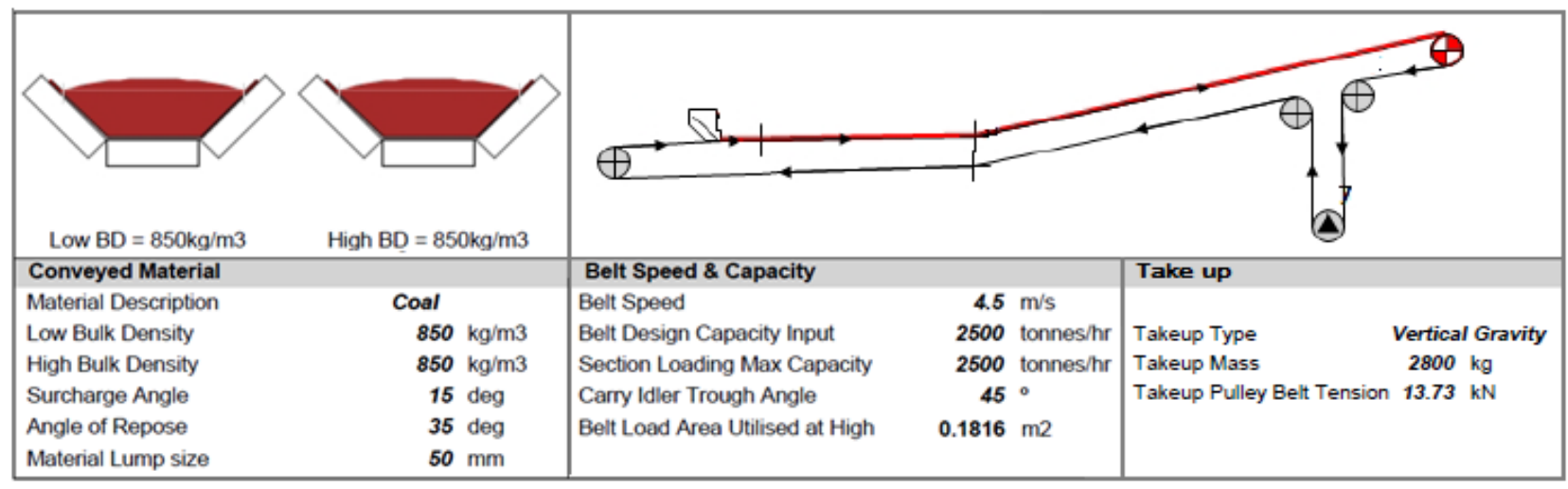

Fig. 8. Running DEM obtain a basic parameter

Simulation in Figure 9 as preliminary to illustrate in full load on the belt as design capacity of 2500 tons per hour (tph) with the parameter of Figure 8 , by the condition before improvement. The turbulence from feed chute then the coal on the belt is in dynamic accelerations and uneven distribution, the coal flow is not stable outgoing from the settling zone which is resulting spillage outgoing the belt. In other side, the occurrences of the spillage also when the metal detector catches up the metal contamination and conveyor system trip, the coal is built up inside of the settling zone 
with the formation and high peak of a repose angle, but operators restart the conveyor system while the coal accelerates in uneven distribution.

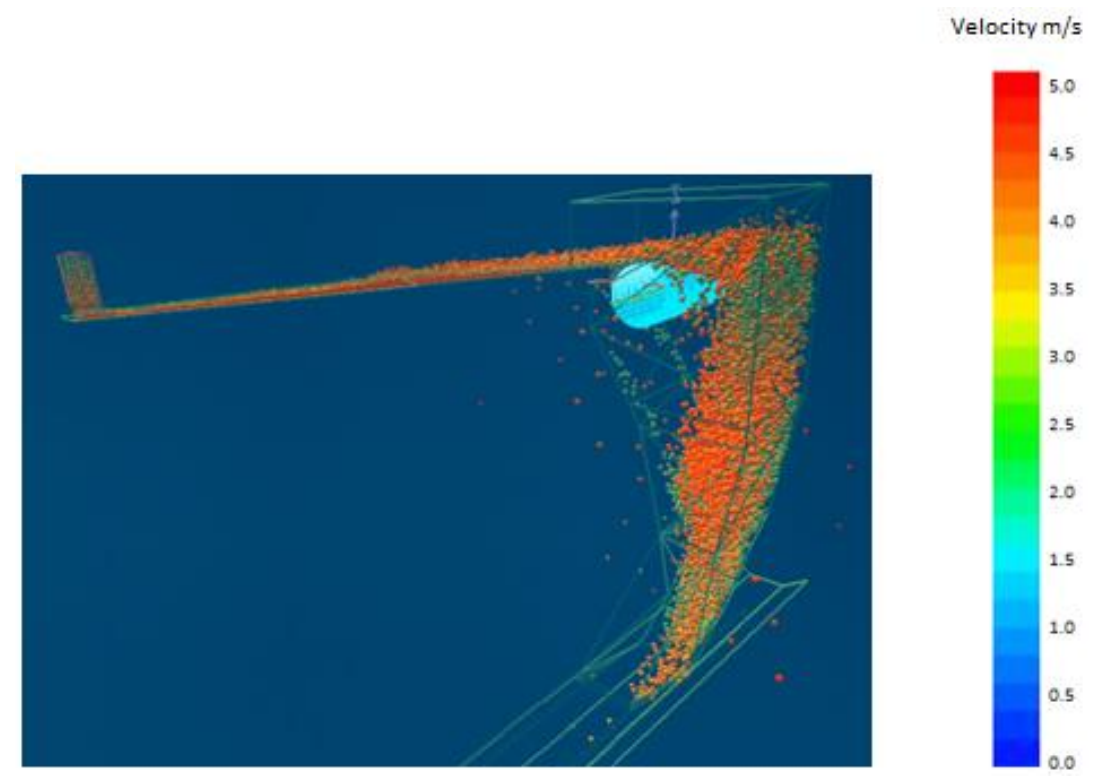

Fig. 9. DEM Simulation conveyor operational without knife gate

\section{Table 3}

Analysis angle and bulk material characteristics

\begin{tabular}{|c|c|c|c|c|}
\hline \multicolumn{5}{|l|}{ Flowability } \\
\hline Very smooth & Smoothly & \multirow{3}{*}{$\begin{array}{l}\text { Normal } \\
20^{\circ}\end{array}$} & Less smooth & \multirow[t]{2}{*}{ Not smooth } \\
\hline Surcharge angle & & & & \\
\hline $5^{\circ}$ & $10^{\circ}$ & & $25^{\circ}$ & $30^{\circ}$ \\
\hline \multicolumn{5}{|l|}{ Angle of repose } \\
\hline $0-19^{\circ}$ & $20-29$ & $30-34^{\circ}$ & $35-39^{\circ}$ & $>40^{\circ}$ \\
\hline \multicolumn{5}{|c|}{ Material characteristics } \\
\hline $\begin{array}{l}\text { Fine grain size and } \\
\text { uniform, relative } \\
\text { grain shape round, } \\
\text { very wet or very } \\
\text { dry like: silica sand } \\
\text { dry, cement and } \\
\text { etc. }\end{array}$ & $\begin{array}{l}\text { Particle shape } \\
\text { relatively round, } \\
\text { Surface dry and } \\
\text { slippery specific } \\
\text { gravity medium, } \\
\text { like: grains and bean } \\
\text { grain }\end{array}$ & $\begin{array}{l}\text { Shape does not } \\
\text { regular, granular or } \\
\text { chunks with specific } \\
\text { gravity medium, } \\
\text { like: anthracitic } \\
\text { coal, clay, and etc. }\end{array}$ & $\begin{array}{l}\text { Bulk material } \\
\text { generally like coal } \\
\text { bituminous, stone } \\
\text { and ore mine, and } \\
\text { etc. }\end{array}$ & $\begin{array}{l}\text { Shape does not regular, } \\
\text { stringy, fibrous, mutual } \\
\text { lock like chopped wood, } \\
\text { sand for casting ones } \\
\text { already hardened }\end{array}$ \\
\hline
\end{tabular}

Table 4

\begin{tabular}{ll} 
Angle repose rate & \\
\hline Angle of repose (degrees) & Type of flow \\
\hline$<20$ & Excellent \\
$20-30$ & Good \\
$30-34$ & Passable \\
$>40$ & Very poor \\
\hline
\end{tabular}

In the operation of the belt conveyor, each material to be moved will have flowability, angle of surcharge, and angle of repose which is different from other materials and depending on its characteristics. Those are the relationship between flowability, material characteristics, angle of surcharge, and angle of repose $[5,7]$. 


\subsection{Modeling Operational With a Knife Gate in Settling Zone}

The choice of the optimum conveyor system depends on full knowledge of the construction characteristics and the forces involved that apply themselves to all the system components [6]. The utilization of adequate accessories to pattern the coal in the discharge yields corresponding improvements to increase the life of the installation with minor maintenance $[11,12]$. By correctly modeling the individual properties of a system, its complex, and often-chaotic behavior, can be analyzed, altered, and improved $[13,14]$. Coal impact on the belt is at a reverse angle causing significant turbulence and sliding shear work against the receiving belt. DEM simulation of coal flow can identify potential problems and guide engineers on the "best practice", it is also can minimize degradation that produces dust product, minimizes gas turbulence that suspends dust, and directs and regulates the flow of transfers and minimizes spillage $[12,14]$. Characteristic of coal flow passing the settling zone influencing of belt conveyor capacity [15]. The influence of the coal flowability on the belt greatly determines the smooth loading onto the receiving belt conveyor. The Discrete Element Method (DEM) is a reliable and powerful tool to study and predict the flow of particles [1619]. A tool that is simulated is the gate for patterning the coal in the settling zone before outgoing to the belt. The following section a simulation of DEM demonstrates the influence from a gate design against the coal flow, and the acceleration as shown in Figure 10. All parameters that were inputted into DEM as the previous simulation in Figure 9.

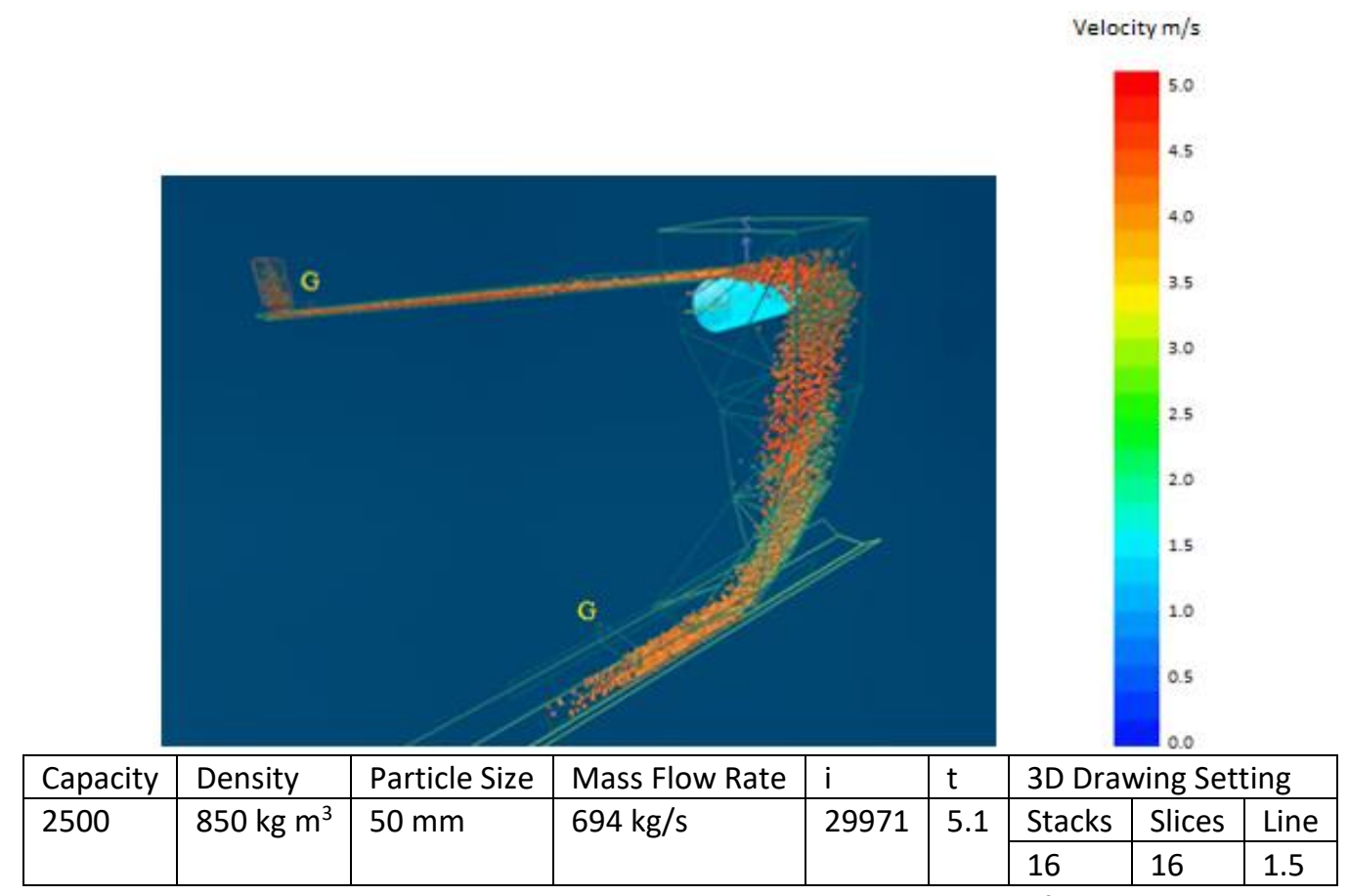

Fig. 10. DEM Simulation conveyor operational with knife gate

These results presented in Figure 10 has assumed that the two knife gates on the up and downstream of the conveyors are activated and well-functioned. Insert the gate 1.5 meters from the end of the settling zone with $\mathrm{G}$ initial. The peak angle of the coal has been cut inside before outgoing, the illustrates an improvement for the belt load during transferring the bulk material. This second simulation is to prove a case study more in-depth.

On the other hand, there are two factors that can impact the material spill. First, belt tension contact wraps onto pulley causing acceleration on the receiving belt behind the material stream 
owing to belt flexural stiffness [20]. Second, due to mistracking, there is indeed a rip on the edge side of the belt [21]. This reduces the cross-sectional area of the material on the belt.

\section{Result and Discussion}

The result from the preliminary running of DEM, the basic parameters are obtained such as repose angle $35^{\circ}$, surcharge angle $15^{\circ}$, troughed angle $45^{\circ}$, belt load area utilized at high $0.1816 \mathrm{~m}^{2}$, with particles size $50 \mathrm{~mm}$, and full capacity as designed with mass flow rate $694 \mathrm{~kg} / \mathrm{s}$. These data serve to simulate of two stages: First, run the conveyor then put the load $2500 \mathrm{Tph}$ by the result particles turbulence from feed chute at the impact troughing and dynamic accelerations, in uneven distribution, unstable flow outgoing from settling zone then spills are inevitable. Second, insert knife gate in the settling zone at the up and downstream conveyor, input the same parameters, and run the conveyor by the resulting particles turbulence from feed chute at the impact troughing, but the coal peak angle straightway cut by the knife gate before passing the settling zone. By applying this method, the coal becomes a uniform stream and the outgoing flow stable with no spillage along the belt. The material characteristic is also interesting to discuss; it contributes a lot to triggering the spillage particularly occurs when the system trips with the load. Referring to Tables 3 and 4, the coal surge angle characteristic is chunks gravity medium anthracitic while the bulk is bituminous of repose. Furthermore, these illustrated are presented in Figure 11 and 12.

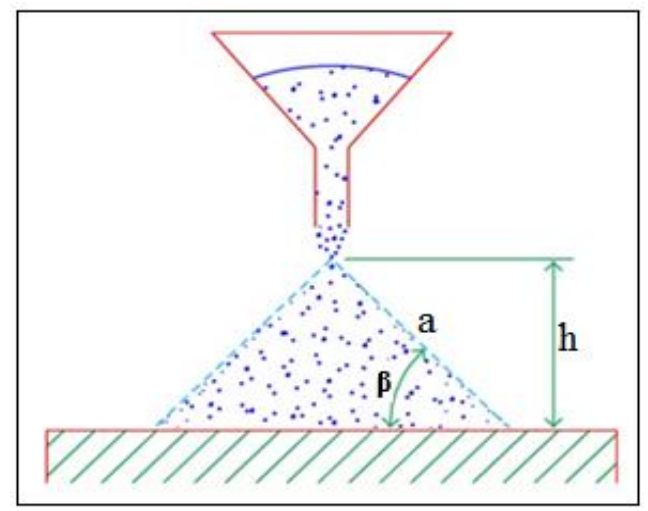

Fig. 11. Motion process of repose angle

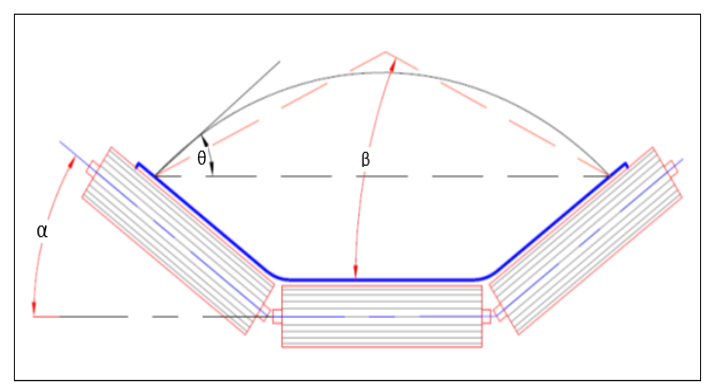

Fig. 12. Motion process of surcharge angle

To define the angle can be formulated by $\operatorname{Sin}(\beta)=\frac{h}{a}$

Surcharge angle, with the dynamic angle of the material, conveyed $(\theta)$, the repose of angle occurs in the settling zone when the conveyor system stops with the load on the belt $(\beta)$, the angle formed 
of the horizontal by the tangent to the material cross-section at the intersection point with the belt in motion, and troughed angle is on the carrying section $(\alpha)$.

Doing analysis in-depth in Tables 3 and 4, the coal is in the category anthracitic chunks gravity medium with bulk bituminous of $35^{\circ}$ of angle repose while desire should be in between $30-34^{\circ}$. It is caused by a shifted slowdown on the slope angle of this bulk material when the system tripping occurs, while operator restarting the conveyor in hurry, those characteristics give a significant triggering spillage. The mismatch numbers of angles for the material inclination against the characteristics has been simulated in DEM and been solved by installing the knife gate, the coal flow outgoing on the belt in good arrangement and more stable.

\subsection{Mechanical Modeling}

Based on DEM simulation and analysis, the following is the recommendation that can be applied to solve the problem in operations of the conveyor in the processing plant that is related to this research. Mechanical modeling is provided to fabricate and install as the follows in Figure 13 and 14.

i. Installation of knife gate for patterning the coal

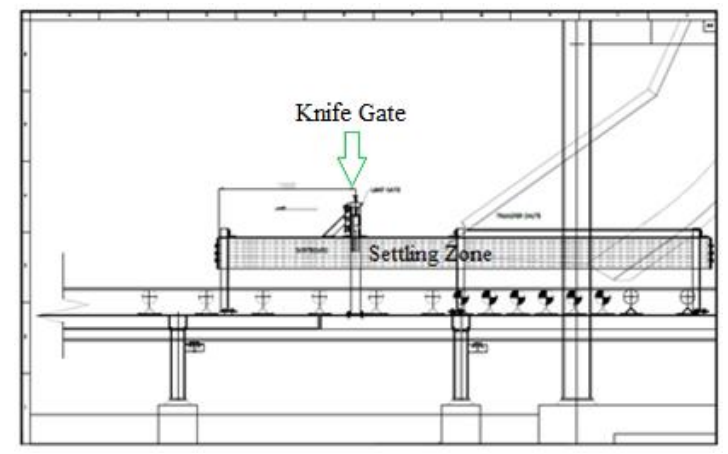

Fig. 13. Knife gate position

The position of installation 1.5 meters before the end of the settling zone aims to give enough space for the surcharging area and prevent blocking the flow when the material is dropped from the upstream conveyor.

ii. Mechanical modeling of knife gate arrangement

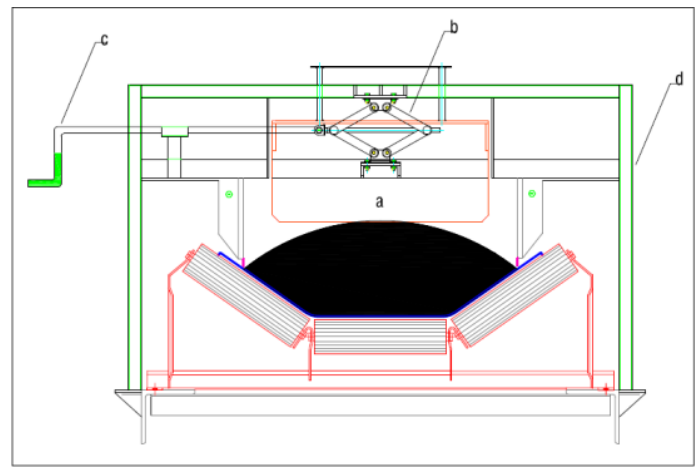

Fig. 14. Patterning gate design 
In order to deliver the effectiveness of the design and better understand the author include the basic information of the tool as follows

i. $\quad$ Knife gate using plate SS400, weight $50 \mathrm{~kg}$

ii. Standard Car scissor jack tire SWL $750 \mathrm{~kg}$, installed opposite position to push down the knife gate

iii. Rotary handle

iv. Stand frame

To define the jack load capacity that is used for operating the knife gate safely, modeling the formula is presented as follows

$F_{B}=$ Force $(\mathrm{kg})$

$F_{D 1}=F_{D 2}$ Force onto arm of the scissor jack thread stud bolt (kg)

$F_{B}=F_{D 1} \operatorname{Cos} x^{0}+F_{D 2} \operatorname{Cos} x^{0}$

$F_{B}=\frac{2 \cdot F_{D}}{\operatorname{Cos} x^{0}}$

$F_{D}=\frac{\frac{F_{B}}{2}}{\cos x^{0}}$

Work with a load of the knife gate is $50 \mathrm{~kg}$, to rotate the handle 15 times for a duration of 90 seconds with a radius of $100 \mathrm{~mm}$, that required the force of $490 \mathrm{~N}$ and power of 51.28 Watt or 0.069 Hp (see Figure 15).

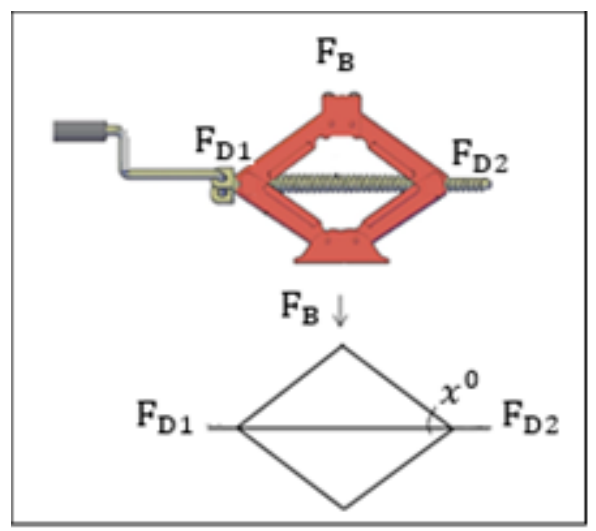

Fig. 15. Jack working force

Figure 16 is the result on checking the top of belt cover rubber stiffness, where the recommendation for the belt hardness are in range of $55-75 \mathrm{HA}$, while the actual condition is in average $76.5 \mathrm{HA}$. It is required to check the belt tension contact wraps onto pulley. Other case such as belt damage on edge side, can be prevented by a guide roller, attached on the edge side of trough roller frames. 


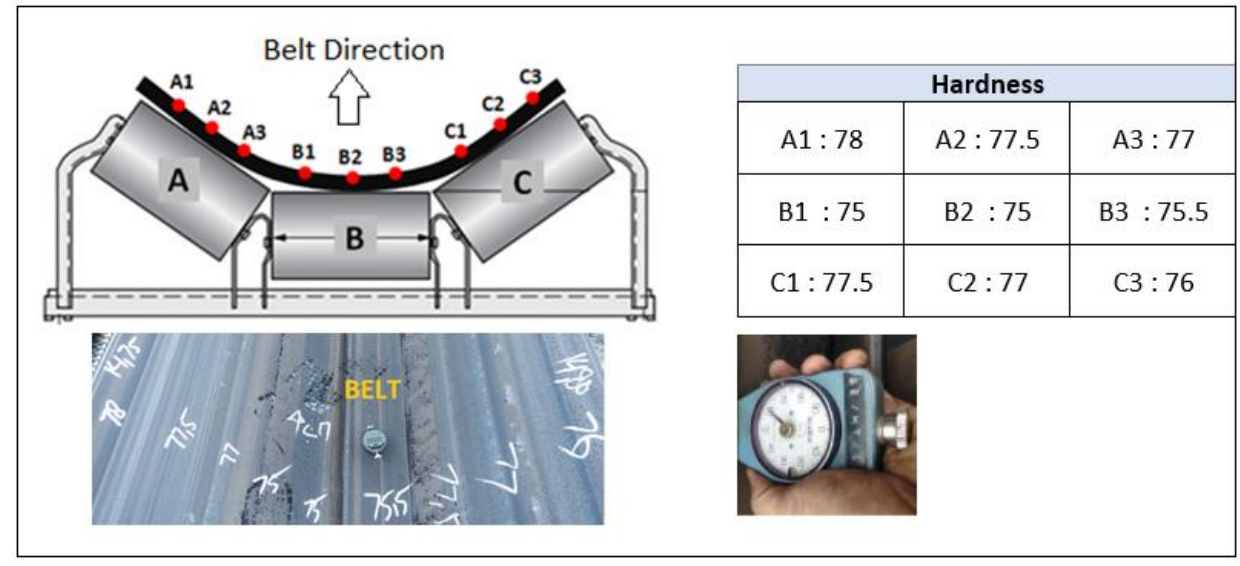

Fig. 16. Rubber stiffness Inspection

\subsection{Performance Indicator}

This section is to prove the success of the research after project completion as in the follows Figure 17 and 18 for the production throughput that is taken from the system of Supervisory Control and Data Acquisition (SCADA), graph for trending load in tons per hour (Tph).

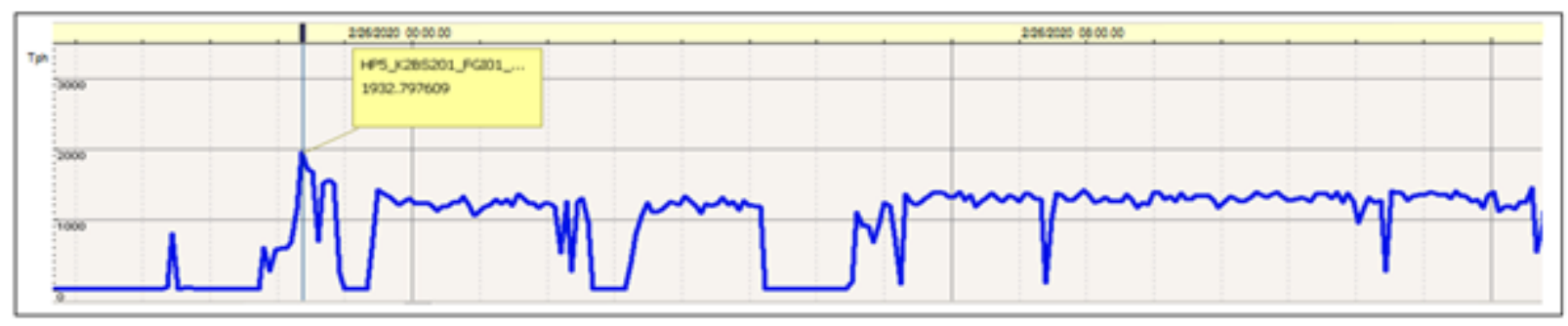

\begin{tabular}{|l|l|l|l|l|l|l|}
\hline Before, 26-02-2020 & 1902.8 & 1777.1 & 1824.0 & 1901.1 & 2015.2 & $\sum Q$ Tph average: 76\% \\
\hline
\end{tabular}

Fig. 17. Coal trending load before improvement

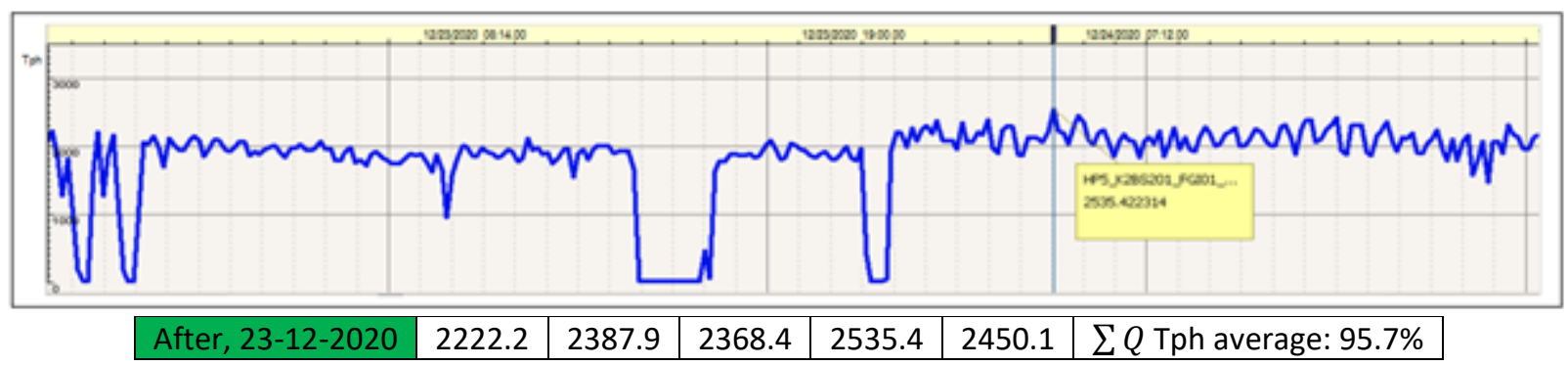

Fig. 18. Coal trending load after improvement

\section{Conclusion}

This paper presents the knife gate method to control the coal flowability in the settling zone and to ensure the belt conveyor runs in stable condition without spillage in handling solid bulk materials. The knife gate method was used for simulation by using DEM software, and including the analysis for the characteristic of the materials. Mechanical modeling was developed by referring to the simulation result, and the calculation model has also been provided to operate the knife gate safely.

The performance indicator resulted from this tool is as appropriateness of the flowability and accelerating load, no-spill along the belt conveyor, and transferring the coal above $95 \%$ compared to the conveyor design while before improvement just average $76 \%$ with full power consumption. By 
increasing the load capacity, the erratic throughput can be eliminated, and the production planner can put the target more accurate.

Besides those advantages, the other benefits are reducing the operational cost due to double handling the coal, components life cycle, man hours for maintaining the belt conveyors, optimizing in using resources such as unit wheel loader, operator, technician, and increase the plant reliability and availability with the green operations.

\section{Acknowledgement}

This research was supported by Advanced Manufacturing Group, Manufacturing Engineering Section, Universiti Kuala Lumpur Malaysian Spanish Institute and PT. ABC Coal Mining Company in Central Kalimantan, Indonesia.

\section{References}

[1] Zhang, Shirong, and Xiaohua Xia. "Optimal control of operation efficiency of belt conveyor systems." Applied Energy 87, no. 6 (2010): 1929-1937. https://doi.org/10.1016/j.apenergy.2010.01.006

[2] He, Daijie, Yusong Pang, Gabriel Lodewijks, and Xiangwei Liu. "Healthy speed control of belt conveyors on conveying bulk materials." Powder technology 327 (2018): 408-419. https://doi.org/10.1016/j.powtec.2018.01.002

[3] Doroszuk, Błażej, and Robert Król. "Analysis of conveyor belt wear caused by material acceleration in transfer stations." Mining Science 26 (2019). https://doi.org/10.37190/msc192615

[4] M. G. S. R. Todd Swinderman, Andrew D. Marti, Larry J. Goldbeck, Daniel Marshall, R. Todd Swinderman, Andrew D. Marti, Larry J. Goldbeck, Daniel Marshall, Mark G.Strebel. "Foundations." Illionis, 2009.

[5] CEMA. "Conveyor Equipment Manufactures Association. 2014 -Belt Conveyors for Bulk Materials $7^{\text {th }}$." USA. 2014.

[6] Shah, K. P. "Construction and maintenance of belt conveyors for coal and bulk material handling plants." (2018): 1269.

[7] G. A. Schultz. "Belt Conveyors for Bulk Materials." Plant Eng. (Barrington, Illinois). 29, no. 18, (1975): 95-98.

[8] Otto, Hendrik, and Andre Katterfeld. "Belt Mistracking-Simulation and Measurements of Belt Sideways Dynamics." University of Magdeburg, Chair of Material Handling Universitätsplatz 2 (2019): 39104.

[9] He, Daijie, Yusong Pang, and Gabriel Lodewijks. "Green operations of belt conveyors by means of speed control." Applied Energy 188 (2017): 330-341. https://doi.org/10.1016/i.apenergy.2016.12.017

[10] Ilic, D., A. Roberts, C. Wheeler, and A. Katterfeld. "Modelling bulk solid flow interactions in transfer chutes: Shearing flow." Powder Technology 354 (2019): 30-44. https://doi.org/10.1016/i.powtec.2019.05.058

[11] Geng, Qi, Huijian Zhang, Xiaohui Liu, and Xuebin Wang. "Numerical study on the rock muck transfer process of TBM cutterhead with clump strategy based on discrete element method." Tunnelling and Underground Space Technology 91 (2019): 103000. https://doi.org/10.1016/i.tust.2019.103000

[12] Chao, Jesús. "Fretting-fatigue induced failure of a connecting rod." Engineering Failure Analysis 96 (2019): 186-201. https://doi.org/10.1016/i.engfailanal.2018.10.006

[13] llic, Dusan, A. Roberts, and C. Wheeler. "Modelling bulk solid interactions in transfer chutes: Accelerated flow." Chemical Engineering Science 209 (2019): 115197. https://doi.org/10.1016/j.ces.2019.115197

[14] Nordell, Lawrence, and Alexander Potapov. "Novel comminution machine may vastly improve crushing-grinding efficiency." In Sixth international conference on semi-autogenous high press. Grinding technology. 2015.

[15] Nata, Yudi, Yana Mulyana, Oscar Haris, and Muhammad Saripul Hidayat. "Optimizing the V Flow Model on the Belt Conveyor in Getting the Optimal Coal Flow Rate with CFD Method." In 2018 International Conference on Computing, Engineering, and Design (ICCED), pp. 13-17. IEEE, 2018. https://doi.org/10.1109/ICCED.2018.00013

[16] Mascarenhas, Fernando Pereira, Alexandre Luiz Amarante Mesquita, and André Luiz Amarante Mesquita. "Simulation of transfer chute operation using the discrete element method." In IBERO-LATIN AMERICAN CONGRESS ON COMPUTATIONAL METHODS IN ENGINEERING, 34th. Pirenópolis: CILAMCE, 2013.

[17] Gao, Yuan, Tiezhu Qiao, Haitao Zhang, Yi Yang, Yusong Pang, and Hongyan Wei. "A contactless measuring speed system of belt conveyor based on machine vision and machine learning." Measurement 139 (2019): 127-133. https://doi.org/10.1016/i.measurement.2019.03.030

[18] Martinetti, Alberto, Leonardus Adriana Maria van Dongen, and Raffaele Romano. "Beyond Accidents: A BackAnalysis on Conveyor Belt Injury for a Better Design for Maintenance Operations." American journal of applied sciences 14, no. 1 (2017): 1-12. https://doi.org/10.3844/ajassp.2017.1.12

[19] Shen, Jiahe, Craig Wheeler, Dusan Ilic, and Jian Chen. "Application of open source FEM and DEM simulations for $\begin{array}{lllll}\text { dynamic belt deflection modelling." Powder Technology } 357 & \text { (2019): 171-185. }\end{array}$ 
https://doi.org/10.1016/i.powtec.2019.08.068

[20] A. Harrison. "Dynamics of high-modulus belts with distributed mass and friction." Journal of Advanced Research in Applied Mechanics 15, no. 1 (2015): 10-19.

[21] Harrison, A. "Defect-induced torques in axially strained orthotropic composite belts and plates." Journal of Advanced Research in Applied Mechanics 17, no. 1 (2016): 14-24. 